\title{
Developmental responses to UV-B radiation in common frog Rana temporaria embryos from along an altitudinal gradient
}

\author{
Olivier Marquis · Claude Miaud · Jean-Paul Lena
}

Received: 15 May 2007/ Accepted: 4 November 2007/Published online: 9 January 2008

(C) The Society of Population Ecology and Springer 2008

\begin{abstract}
Solar ultraviolet radiation (UV) is harmful for developing amphibians. As UV increases with altitude and latitude, it is suggested that high altitude and latitude populations have evolved tolerance to high levels of UV. Using laboratory experiments, we tested the hypothesis that Rana temporaria populations from several altitudes (4382,450 $\mathrm{m}$ above sea level) were adapted to UV by assessing the effects of artificial UV on embryos mortality rate, malformations, and body length at hatching. We also tested the protective role of the jelly surrounding the embryos. Without artificial UV exposure, hatching success decreased with altitude of the population. Malformation rates were low for all populations (mean $1.36 \%$ ), and hatching size increased with altitude. The artificial UV (UV-B, UV-A, and visible) used was similar to the solar spectrum received at high altitude. Exposed embryos had performance similar to that of embryos without exposure: a decreased hatching success with altitude and a low malformation rate (mean $0.85 \%$ ). However, hatching size did not vary with altitude, and UV-exposed embryos tended to be smaller at hatching than non-exposed embryos. Removal of the protective jelly envelope greatly decreased the performance of UVexposed embryos: hatching success strongly decreased with altitude and embryos of the highest population
\end{abstract}

O. Marquis $(\bowtie) \cdot$ C. Miaud $(\bowtie)$

UMR CNRS 5553 Laboratoire d'Ecologie Alpine,

Université de Savoie, 73376 Le Bourget du Lac, France

e-mail: olivier.marquis@u-psud.fr

C. Miaud

e-mail: claude.miaud@univ-savoie.fr

J.-P. Lena

UMR CNRS 5023 Laboratoire d'Ecologie des Hydrosystemes

Fluviaux, Université Claude Bernard, LYON I,

69622 Villeurbanne Cedex, France
(2,450 m asl) did not develop. Malformation reached $4.98 \%$, without population differences, and hatching size of embryos without jelly was smaller than hatching size of non-manipulated embryos with no population effect. This study demonstrates that lowland jellyless embryos were less sensitive (i.e., exhibited a higher survival rate) than highland embryos and, on the other hand, that the jelly envelope was a more efficient protection for embryos in highland than in lowland populations. A trade-off hypothesis is presented to explain this difference in UV tolerance and protection among populations: in a harsh, highland environment (i.e., with a curtailed activity period), embryos have to invest in development and growth and, thus, embryo protection should be a female investment (via the jelly). In a lowland environment, embryonic growth and development are less constrained and embryos are able to invest and use protection or repair mechanisms inherited from their parents.

Keywords Altitude - Amphibian · Embryos · Local adaptation $\cdot$ UV exposure

\section{Introduction}

The flux of ultraviolet radiation (UV) reaching the surface of the earth is an important environmental stressor for many organisms over evolutionary time scales (Cockell and Blaustein 2001; Blaustein and Belden 2003; Licht 2003; Palen et al. 2002). The recent increases of UV reaching the surface owing to stratospheric ozone depletion (Tevini 1993) has made the vulnerability of organisms to UV a concern of wide interest.

Amphibian embryos that develop surrounded by a transparent jelly coat could make this group particularly at 
risk to UV increase (Blaustein and Wake 1995). Furthermore, the worldwide decline of amphibian populations since 1960 (Houlahan et al. 2000) overlaps the time scale of the global UV increasing. Population declines have been widespread even in areas not exposed to local anthropogenic stressors (Blaustein and Belden 2003). Consequently, over the past decade, numerous studies have focused on the potential implications of increases in UV flux in the decline of amphibian populations (see Blaustein and Belden 2003; Licht 2003 for reviews).

Since the UV flux reaching the earth's surface varies regionally with latitude and altitude, species do not experience a uniform level of UV flux everywhere (Belden et al. 2000; Merilä et al. 2000a). Species living at high altitude or latitude may have developed behavioural adaptations (e.g., in habitat selection or activity period; Sinsch 1984; Blaustein and Belden 2003; Palen et al. 2002), and/or tolerance mechanisms to UV stress compared to those living at lower altitudes or latitudes (Corn 1998; Hofer and Mokri 2000; Belden and Blaustein 2002; Blaustein and Belden 2003). For example, the jelly envelope surrounding embryos is a potential UV protection (Grant and Licht 1995; Licht and Grant 1997; Crump et al. 1999; Hofer and Mokri 2000; Häkkinen et al. 2001; Smith et al. 2002; but see Räsänen et al. 2003); the spectral absorbance within the range of UV-B of this envelope has been found to vary between 99 and $40 \%$ in several species (Licht 2003). Large variations have also been observed in photo-protective compounds such as the melanin synthesized in eggs, embryos, or tadpoles (Blaustein and Belden 2003). Finally, DNA-damage repair mechanisms (e.g., photo-enzymatic and nucleotide excision repairs) can also vary strongly among species (Blaustein et al. 1994; Palen et al. 2002).

Species with large geographic ranges are exposed to variable solar radiation levels, but studies on UV tolerance among populations are particularly scarce: the long-toed salamander (Ambystoma macrodactylum) had a higher tolerance at higher altitudes (Belden et al. 2000), whereas UV tolerance varies among Scandinavian populations of common frog (Rana temporaria), but without latitudinal effect (Pahkala et al. 2002). This frog species provides model populations in which to study UV tolerance. It is widespread in Europe, living from sea level up to $2,700 \mathrm{~m}$ in the Alps (Gasc et al. 1997). Breeding takes place in shallow water and embryos are directly exposed to solar radiation (Guyétant et al. 1994). Interpopulational variations in life history traits along altitudinal or latitudinal gradients were reported (Miaud and Merilä 2001; Laugen et al. 2003).

The aim of this study was to compare UV tolerance among $R$. temporaria populations widespread along an altitudinal gradient. Since a $19 \%$ UV-B increase per $1,000 \mathrm{~m}$ is observed in the Alps (Blumthaler et al. 1992), we tested the hypothesis that highland populations exhibited higher UV exposure tolerance than lowland populations. The genetic characteristics of embryos come from the parents, while only females produce the jelly envelope surrounding the eggs just before spawning. This situation allows us to test the role that the jelly plays in UV protection and an eventual maternal investment in photoprotection of embryos. Both hypotheses were tested with controlled levels of UV in laboratory experiments.

\section{Materials and methods}

\section{Species and populations}

Rana temporaria breeds in a wide range of freshwater habitats from northern Spain to the northern parts of Fennoscandia and from sea level to $2,745 \mathrm{~m}$ in the Alps (Vences et al. 2003). Clutches are deposited in shallow water and embryos are directly exposed to solar radiation. We collected a total of 12 clutches (see Table 1 for details) (numbers of eggs per clutch were 500-1,500) in four populations at $438 \mathrm{~m}\left(45^{\circ} 32^{\prime} \mathrm{N}, 5^{\circ} 53^{\prime} \mathrm{E}\right.$, two clutches), $860 \mathrm{~m}\left(45^{\circ} 41^{\prime} \mathrm{N}, \quad 6^{\circ} 17^{\prime} \mathrm{E}\right.$, three clutches $), \quad 1,318 \mathrm{~m}$ $\left(45^{\circ} 41^{\prime} \mathrm{N}, 6^{\circ} 01^{\prime} \mathrm{E}\right.$, three clutches $)$ and $2,450 \mathrm{~m}\left(45^{\circ} 04^{\prime} \mathrm{N}\right.$,

Table 1 Experimental treatments of $R$. temporaria embryos from four populations varying in altitude

\begin{tabular}{|c|c|c|c|c|c|c|}
\hline \multirow[t]{2}{*}{ Starting date } & \multirow[t]{2}{*}{ Altitude (m) } & \multicolumn{2}{|c|}{ UV-B exposed group } & \multicolumn{2}{|l|}{ Control group } & \multirow{2}{*}{$\begin{array}{l}\text { Number } \\
\text { of family } \\
\text { per population }\end{array}$} \\
\hline & & Jelly & Jelly removal & Jelly & Jelly removal & \\
\hline 3 April & 438 & $\mathrm{~A} / \mathrm{B}(\times 2)$ & $\mathrm{A} / \mathrm{B}(\times 2)$ & $\mathrm{A} / \mathrm{B}(\times 2)$ & $\mathrm{A} / \mathrm{B}(\times 2)$ & 2 \\
\hline 22 March & 860 & $\mathrm{C} / \mathrm{D}(\times 2)$ & $\mathrm{C} / \mathrm{D}(\times 2)$ & $E(\times 2)$ & $E(\times 2)$ & 3 \\
\hline 19 April & 1,318 & $\mathrm{~F} / \mathrm{G}(\times 2)$ & $\mathrm{F} / \mathrm{G}(\times 2)$ & $\mathrm{H}(\times 2)$ & $\mathrm{H}(\times 2)$ & 3 \\
\hline \multirow[t]{2}{*}{12 May } & 2,450 & $\mathrm{I} / \mathrm{J} / \mathrm{K} / \mathrm{L}(\times 2)$ & $\mathrm{I} / \mathrm{J} / \mathrm{K} / \mathrm{L}(\times 2)$ & $\mathrm{I} / \mathrm{J} / \mathrm{K} / \mathrm{L}(\times 2)$ & $\mathrm{I} / \mathrm{J} / \mathrm{K} / \mathrm{L}(\times 2)$ & 4 \\
\hline & $\begin{array}{l}\text { Number of } \\
\text { family per } \\
\text { group }\end{array}$ & $\sum=10$ & & $\sum=8$ & & $\sum=12$ \\
\hline
\end{tabular}

A letter specifies each family. Each family was submitted to both treatments (jelly removal or not), which was replicated one time $(=\times 2)$ 
$6^{\circ} 24^{\prime} \mathrm{E}$, four clutches) in the north-western French Alps (Department of Savoie) in 2003. As breeding time differed among populations according to altitude, the clutches were collected from March at $438 \mathrm{~m}$ to mid-May at 2,450 m. Only clutches for which embryonic development did not exceed stage 4 (Gosner 1960) were collected to ensure that clutches had been fertilized within $24 \mathrm{~h}$. The variation of number of clutches sampled by populations was related to the number of freshly deposited spawns available in the field.

\section{Experimental treatment}

Clutches were stored in a room maintained at $4{ }^{\circ} \mathrm{C}$ immediately after arrival at the laboratory. Each clutch was separated into two groups of 200 eggs. One group experienced UV-B exposure (=exposed group) while the other one did not (=control group). Because of technical problems during the experiment, control groups for the population from 860 and $1,318 \mathrm{~m}$ had to be performed with eggs of the same population but from another clutch than those exposed to UV-B (total number of tested clutches $=12$; see Table 1 for details). Then, each group was split into four subsamples of 50 eggs: two experienced the removal of the jelly envelope (=jelly treatment) while the two others did not (=jelly control). We manually removed the jelly coat, as chemical removal alters embryo survival (Räsänen et al. 2003). Eggs of both treatments (i.e., jelly treatment and jelly control) were then placed within a circular glass vessel $(10 \mathrm{~cm}$ in diameter, $8 \mathrm{~cm}$ in depth) doubly compartmented: eggs of one treatment were placed in a central dish $(5 \mathrm{~cm}$ in diameter, $7 \mathrm{~cm}$ in depth) while the eggs of the other treatment were placed at the periphery. Eggs were distributed on a single layer within each compartment to ensure homogeneous radiation exposure.

The UV exposure was performed with a solar simulator (SUNTEST CPS plus, ATLAS). The light was provided by an Arc Xenon lamp generating the full solar spectrum with UV-B (280-315 nm, 0.4\%), UV-A (315-380 nm, 7\%), and visible $(380-800 \mathrm{~nm}, 92 \%)$. This artificial spectrum is similar to the solar spectrum measured at the High Alpine Research Station in Jungfraujoch, Switzerland $\left(46^{\circ} 30^{\prime} \mathrm{N}\right.$, $8^{\circ} 04^{\prime} \mathrm{E} ; 3,576 \mathrm{~m}$ asl) and Innsbruck, Austria $\left(47^{\circ} 16^{\prime} \mathrm{N}\right.$, $11^{\circ} 23^{\prime} \mathrm{E}$; $577 \mathrm{~m}$ asl), that is, UV-B $=0.42$ and $0.33 \%$, and $\mathrm{UV}-\mathrm{A}=5.5$ and $5.3 \%$, respectively (Blumthaler et al. 1992). Embryos were exposed $6 \mathrm{~h}$ per day to a dose of $500 \mathrm{~W} \mathrm{~m}^{-2}$, which corresponded to a cumulative dose of $10.8 \mathrm{MJ} \mathrm{m}^{-2}$ per day. At mean latitude, the global direct irradiance can reach up to $1,000 \mathrm{~W} \mathrm{~m}^{-2}$ under a clear sky, and the mean daily cumulative global radiation (for unclouded days of summer months) was $36.5 \mathrm{MJ} \mathrm{m}^{-2}$ at $3,576 \mathrm{~m}$ asl and $29.45 \mathrm{MJ} \mathrm{m}^{-2}$ at $577 \mathrm{~m}$ asl (Blumthaler et al. 1992), at meteorological stations with complete open horizon.

Two glass vessels were exposed simultaneously in the Suntest, allowing us to treat two pairs of samples at the same time (i.e., two replicates of the same family). Because clutches were laid at different times at the different altitudes, we were able to expose each set of eggs for $6 \mathrm{~h} / \mathrm{day}$. To ensure the same ontogenic UV exposure for each population, the experiment lasted from fertilization to stage 25 (Gosner 1960). As the developmental speed between fertilization and stage 25 increased with the altitude of the population (Marquis and Miaud 2008), length of exposure decreased with the altitude of the population (respectively $12,12,10,7$ days for populations from $438,860,1,318$ and $2,450 \mathrm{~m}$ ). Each glass vessel was equipped with a cooling system to maintain an ambient temperature within each vessel, and water temperature was controlled daily (mean temperature $\pm \mathrm{SD}=18^{\circ} \mathrm{C} \pm 1.08$ ). For the UV control, vessels were stored in a separate room maintained at $18^{\circ} \mathrm{C}$ and lighted by aquarium tubes (Sylvania Standard F36W, white), which produce no UV-A or UV-B.

In both rearing situations, dead embryos were removed daily. Water was changed every 3 days. Animals that survived to the acquisition of complete mobility (i.e., stage 25; Gosner 1960) were considered successfully hatched. These animals were then removed from the rearing unit and preserved in $80 \%$ ethanol. Two morphological variables were then recorded: malformation (flexure of the tail and/or oedema) and hatching size, measured from tip of the nose to tip of the tail on digital pictures using GIS software (Mapinfo).

\section{Statistical analyses}

Hatching success, absence of morphological malformation, and size of hatching were used as performance indicators. We first verified if, in the absence of UV exposure (UV control), the embryo performances varied with the jelly treatment and the elevation of the population. Then, we tested whether the performance of embryos (jelly control and jelly treatment) varied according to the population elevation and UV treatment. As eggs belonging to the same clutch and sub-sample that experienced the same compartment in the rearing system cannot be considered as independent data points, we used a mixed model to perform analyses. Specifically, we introduced both clutch origin and the interaction of clutch origin $\times$ treatment as two levels of random effect. Therefore, we used a generalized linear mixed model with binomial errors and a logit link to analyse hatching success and malformation (proc mixed; SAS Institute 2000), and we used a linear mixed model to analyse size performance (proc mixed; 
SAS Institute 2000). In all analyses, the effects of both factors, that is, the population elevation and the treatment (jelly or UV treatment), as well as their interactive effect, were introduced into the model. A non-sequential test was used to assess the significance of each fixed effect introduced into the model (Type 3 test; SAS Institute 2000). Non-significant terms (among those introduced as fixed effects) were then successively removed to obtain the final model. Exposure duration was correlated with the altitude of populations $\left(r_{\mathrm{s}}=-0.95, P=0.05\right)$, and adding it as a covariate in statistical analysis means that the effect of altitude is lost with no improvement in jelly or UV exposure as an explanatory variable. Observed variation with altitude have thus to be interpreted taking into account variation in UV-B exposure.

\section{Results}

Population of origin and jelly treatment effect in control groups

Embryonic survival to hatching decreased with altitude (Fig. 1a). It was not altered by the jelly treatment nor by the interaction of these two factors (number of clutches $=8$; population: $F_{1,4.97}=23.33 ; P=0.0048$; jelly treatment: $F_{1,9.18}=0.04, \quad P=0.84 ;$ population $\times$ jelly treatment: $F_{1,9.83}=0.62, P=0.45$ ).

The number of deformed tadpoles at hatching was very low: from a total of 590 surviving tadpoles, only 8 were deformed at hatching (embryonic malformation rate $=$ $1.36 \%)$. We did not further analyse these data.

Tadpole size at hatching increased with the altitude of the population of origin, although the largest size was observed for the population at $1,318 \mathrm{~m}$ asl (number of clutches $=8 ;$ population: $F_{1,6.57}=5.80 ; \quad P=0.0492$; Fig. 1b). Embryos with jelly led to larger tadpoles at hatching than embryos without jelly (number of clutches $=8$; jelly treatment: $F_{1,3.49}=16.07, P=0.021$; Fig. 1b). There was, however, a significant non-additive effect between populations and jelly treatment (number of clutches $=8$; population $\times$ jelly treatment: $F_{1,14.4}=8.32$, $P=0.0117)$, that is, manipulated embryos led to smaller tadpoles in three populations while non-manipulated embryos led to larger tadpoles in the remaining 2,540 $\mathrm{m}$ asl population.

Effect of population of origin on embryos exposed to UV-B and protected by the jelly coat

Embryo survival significantly decreased as altitude increased (Fig. 2), but not with the UV treatment, nor the
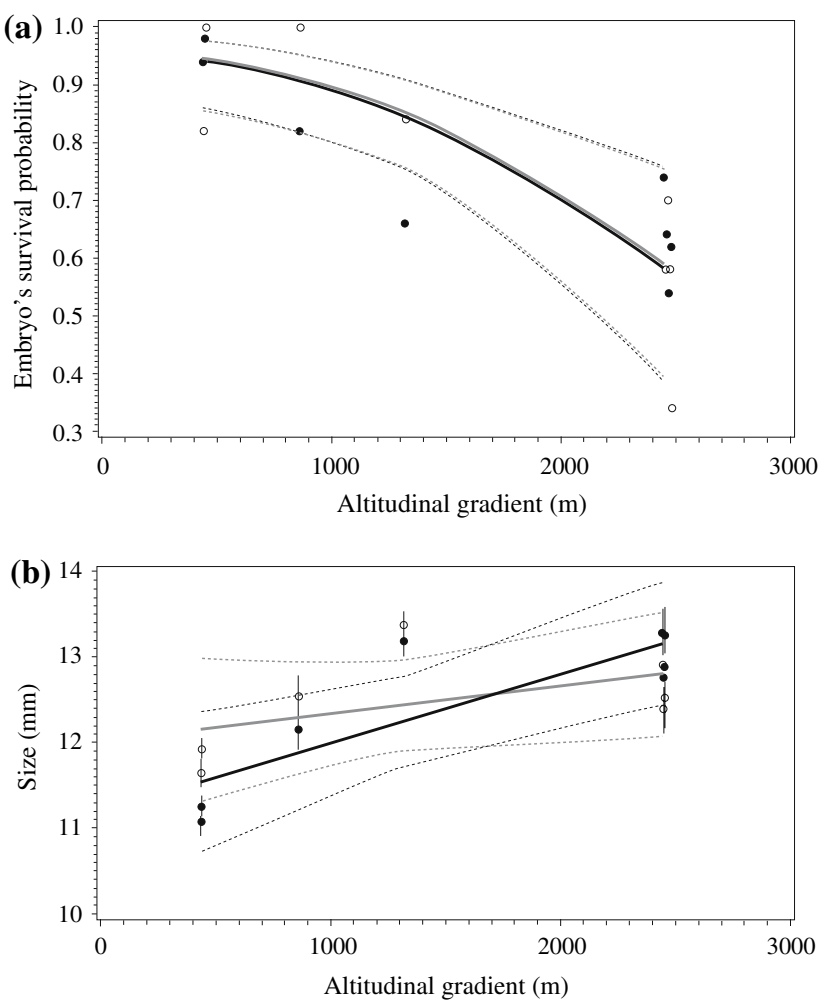

Fig. 1 a Survival at hatching and $\mathbf{b}$ size at hatching of embryos of Rana temporaria that developed with and without jelly envelope according to population of origin (no artificial UV exposure). Filled circles and open circles indicate the survival rate and the size at hatching recorded respectively within the jelly treatment sub-samples and within the jelly control sub-samples. Values are slightly displaced on the horizontal axis for the sake of clarity. Solid lines represent the predicted fixed effect of the altitudinal gradient according to the jelly effect (grey line for the jelly control and black line for the jelly treatment) retained in the model, and dotted lines represent the $95 \%$ confidence interval for the fixed effects

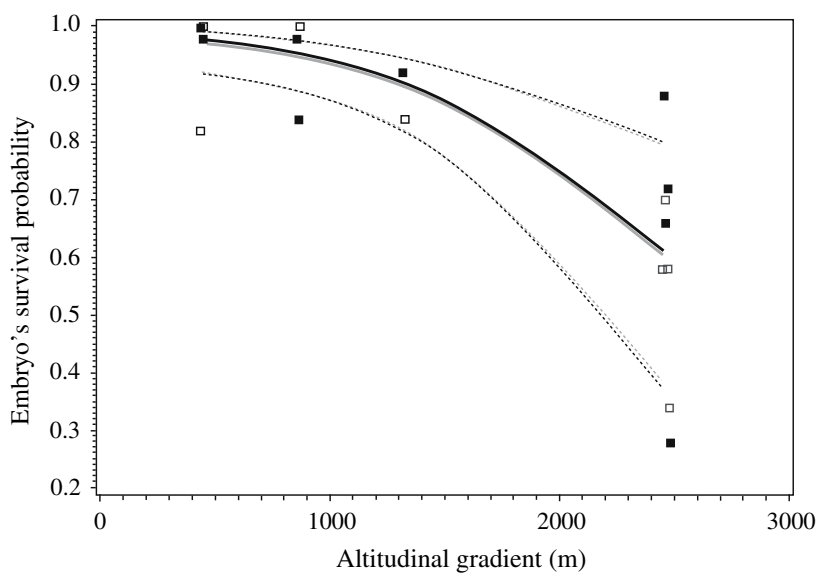

Fig. 2 Survival at hatching of normal embryos of $R$. temporaria exposed to UV treatment according to population of origin. Filled squares and open squares indicate the survival rate at hatching recorded respectively within the UV treatment sub-samples and the UV control ones. Vertical bars represent the standard error of these estimates. See Fig. 1 for the rest of the legend 
interaction of the UV treatment and population (number of clutches $=10$; population: $F_{1,8.72}=21.06 ; P=0.0014$; UV treatment: $F_{1,5.23}=0.79, P=0.41$; population $\times \mathrm{UV}$ treatment: $F_{1,5.03}=0.03, P=0.87$ ).

Despite the UV treatment, the number of deformed hatching was very low: from 705 that survived to hatching, only six tadpoles were found deformed (embryonic malformation rate $=0.85 \%$ ). We did not analyse these data further.

None of the factors (population or treatment) significantly altered the hatching size of normal embryos. However, tadpoles coming from embryos exposed to UV tended to be smaller than tadpoles coming from nonexposed embryos (number of clutches $=10$; population: $F_{1,7.12}=0.22, P=0.65$; UV treatment: $F_{1,6.01}=4.55$, $P=0.077$; population $\times \mathrm{UV}$ treatment: $F_{1,1.75}=2.32$, $P=0.28)$.

Effect of population of origin on embryos exposed to UV-B without jelly protection

As previously observed with embryos non-exposed to UV, the hatching success of embryos exposed to artificial UV decreased as altitude increased (number of clutches $=10$; population: $\quad F_{1,9.90}=44.16 ; \quad P<0.0001 ; \quad$ Fig. $\left.3 a\right)$. Removing the jelly envelope did not alter the hatching success (number of clutches $=10$; jelly treatment: $F_{1,7.88}=0.02$, n.s.). There was a significant non-additive effect of both factors (UV treatment and population) on embryonic survival (number of clutches $=10$; population $\times$ jelly treatment: $F_{1,11.48}=13.49, P<0.0034$ ), that is, the decreasing hatching success with altitude was higher when the jelly envelope was removed from the embryos (Fig. 3a).

Thirty-three of a total of 663 live tadpoles were found deformed (hatching malformation rate $=4.98 \%$ ). A mixed analysis was performed on these data, although the data were found to be under-dispersed (generalized $\chi^{2}=8.07$ with $13 d f$ ). The only significant effect detected was that of jelly removal (number of clutches $=10$; population: $F_{1,14}=0.2, P=0.66$; jelly treatment: $F_{1,3.70}=11.65$, $P=0.030$; population $\times$ jelly treatment: $F_{1,13}=2.86$, $P=0.11$ ). The relative odds ratio of malformation between embryos without jelly and embryos with jelly was 15.1 (CI 95\%: 1.6-139.2).

The hatching size of tadpoles coming from removed jelly embryos was significantly lower than that of tadpoles coming from normal embryos (number of spawns $=10$; $F_{1,6.63}=10.08, P=0.017$; hatching size least square means $\pm \mathrm{SD}=10.91 \pm 0.28$ for $\mathrm{UV}$-exposed embryos and $11.92 \pm 0.22$ for control embryos; Fig. 3b). Neither population nor the interaction of this factor with the jelly
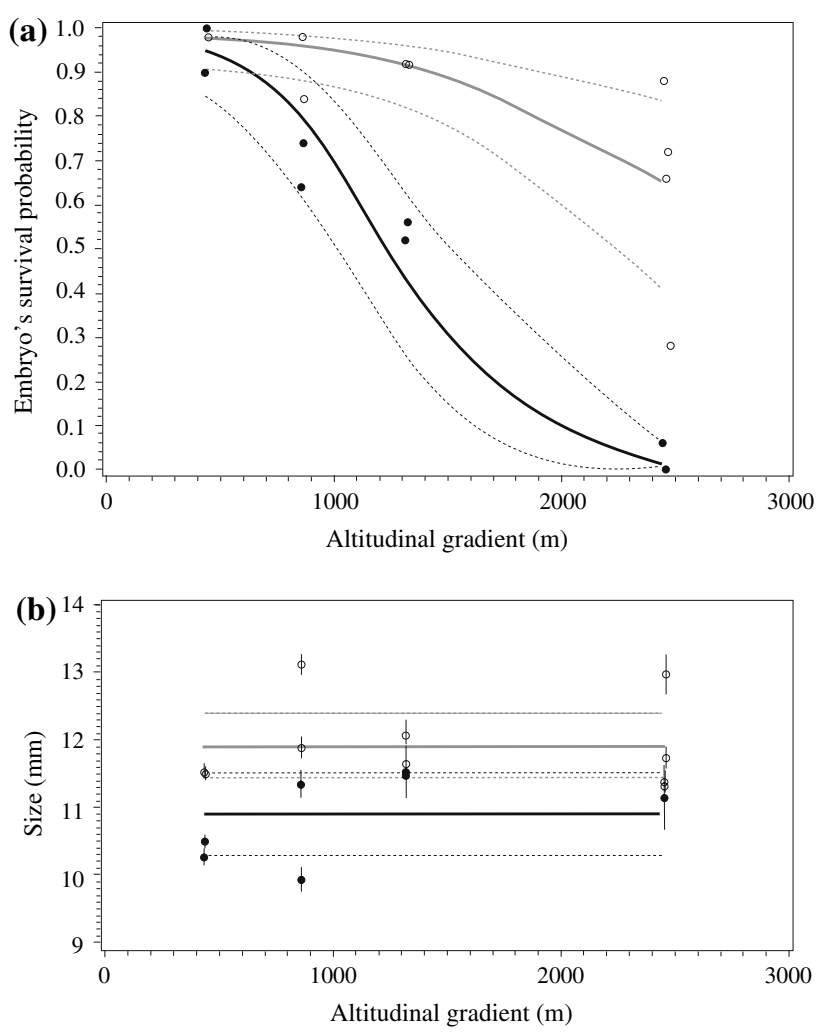

Fig. 3 a Survival at hatching and $\mathbf{b}$ size at hatching of embryo of $R$. temporaria exposed to UV treatment and jelly removal according to the population of origin. See Fig. 1 for the legend

treatment significantly altered the mean hatching size of tadpoles (number of clutches $=10$; population: $F_{1,9.36}=0.31, P=0.59$; population $\times$ jelly treatment: $F_{1,9.54}=3.06, P=0.11$ ).

\section{Discussion}

Overall effect of UV-B exposure on embryonic performance

Without UV exposure, the hatching success of R. temporaria embryo varies among populations, with the lowest rate observed in the highland population (Fig. 1). The reason for this result remains unclear. Pahkala et al. (2000, 2002) have found similar results among $R$. temporaria populations varying in latitude, and hypothesized that laboratory experimental conditions may be more favorable for lower latitude populations. It has been shown that insecticide-resistant genotypes were disadvantaged in the absence of insecticide compared to non-resistant genotypes in the fly Lucinia cuprina (Wood and Bishop 1981). More generally, an increasing stress tolerance induces decreasing individual fitness in absence of stress (Hoffmann and Parsons 1991). Thus, high altitude populations that face 
many environmental stressors have developed adaptations to resist the stressors (Bonin et al. 2006) and, in the absence of stress (i.e., control groups in laboratory conditions), highland embryos may show a lower fitness than those of lowland populations, leading to the observed lower hatching success.

Embryos of $R$. temporaria were able to develop when exposed to a high level of UV-B, and the very low malformation rate observed confirmed that $R$. temporaria is highly tolerant to UV exposure (e.g., Cummins et al. 1999; Hofer and Mokri 2000; Häkkinen et al. 2001; Pahkala et al. 2000, 2001, 2002; Räsänen et al. 2003). This embryonic resistance could be the result of several mechanisms (e.g., jelly envelope protection, embryo cellular compounds such as pigments and physiological resistance, and DNA repair systems). These mechanisms can be closely linked to minimize the effect of UV exposure (see Blaustein and Belden 2003 for a review), but remain to be identified as embryonic protection in $R$. temporaria. Despite the natural increase of UV-B with altitude, embryos of highland populations did not survive better than embryos of lowland populations in our experiments. The faster embryonic developmental rate of highland $R$. temporaria populations compared to that of lowland populations (in laboratory constant temperature conditions; Marquis and Miaud 2008) could also be involved in photo protection, because embryos that reach the tadpole mobile phase as soon as possible can escape solar exposure.

There was a tendency (but non-significant effect) for newly hatched tadpoles from exposed embryos to be smaller than those from non-exposed ones. This hatching size decrease was observed previously in several studies (Merilä et al. 2000b; Pahkala et al. 2000; Marquis and Miaud 2008). UV-B can damage DNA and activate enzymatic-repairing mechanisms (Blaustein et al. 1994; Smith et al. 2002). Such mechanisms could consume part of the energy normally used in embryonic growth and have been proposed to explain the observed lowered size at hatching (Pahkala et al. 2000).

The protective role of the jelly envelope against UV

Removing the jelly envelope induced a strong decrease in hatching success of embryos exposed to high levels of UV$\mathrm{B}$ in comparison to non-exposed embryos. The jelly envelope thus plays an important role in protecting embryos of $R$. temporaria from UV exposure. The jelly removal also induced a decrease in size at hatching (Fig. 3b). The jelly coat surrounding amphibian embryos is composed of glycoproteins, mucoproteins, carbohydrates, and mucopolysaccharids (Salthe 1963), which intercept a part of UV-B radiation (i.e., $7 \%$ for $R$. sylvatica, $14 \%$ for
Bufo americanus, and $6.5 \%$ for R. aurora; Grant and Licht 1995). The absorption maximum of the jelly was at $275 \mathrm{~nm}$ in various anuran species (Ovaska et al. 1997). Hansen et al. (2001) noticed that efficient protection against UV-B would require a maximum UV-B absorption between 294 and $305 \mathrm{~nm}$, which represents the most deleterious range of UV-B wavelengths. In lower UV-B doses than those used in our experiments, the jelly did not play an apparent role in photoprotection in R. temporaria (Räsänen et al. 2003), Hyla regilla, or Bufo canorus (Hansen et al. 2001). The way in which jelly provides better UV-B protection in high altitudes remains unknown. Interspecific variation in jelly UV-B absorption has been documented (Grant and Licht 1995; Ovaska et al. 1997), but, to our knowledge, no interpopulation comparisons of jelly optical characteristics have been performed. Egg size of $R$. temporaria increased with latitude (Laugen et al. 2003) and altitude (Martin and Miaud 1999; Miaud and Merilä 2001) and was strongly linked to maternal effect (Parichy and Kaplan 1995; Räsänen et al. 2005). However, egg size was the size of only the fertilized ovocyte and did not take into account variation in jelly thickness, which can also vary among species (Grant and Licht 1995). Information on jelly thickness and composition in relation with UV protection remains to be collected in anurans. Licht (2003), however, did discuss jelly thickness in relation to UV-B exposure at oviposition sites and duration of embryonic development.

Variation among populations in the protective role of the jelly envelope against UV-B

Jelly removal increased the embryonic mortality rate and embryos without jelly from high altitude populations were strongly more sensitive to high UV levels than those from low altitudes (Fig. 3a) indicating that (1) the protective role of jelly increased with altitude and (2) embryo resistance to UV (i.e., without jelly protection) decreased with altitude.

Faster developmental rate in high altitude populations could have resulted in a biased better performance of high altitude populations in our experiments. Results show that this is clearly not the case with the effect of jelly removal on survival because high altitude populations suffered from an acute mortality despite a shorter length of exposure.

This counter-intuitive result can be interpreted in terms of trade-offs between protection requirements and other embryonic and larval traits. The jelly is deposited around the oocyte at the end of transit within the oviduct, and its composition is thus a direct maternal effect. Cellular compounds of the embryo (e.g., pigments intercepting UV-B), physiological resistance, and DNA repair systems are linked to the embryo genotype (a family effect). The duration of the active period is about 8 months/year at 
$350 \mathrm{~m}$ asl and 3 months/year at 2,300 m asl, and tadpoles unable to metamorphose before the end of this period are eliminated (Guyétant et al. 1994). Given this very short favorable period for embryonic and larval development, we hypothesize that, in highland populations, selection would favour jelly protection (maternal effect), rather than a costly embryonic mechanism against UV-B damage in order to increase the developmental rate and thus minimize the length of embryonic and larval period. Since embryos in highland populations are protected from UV, they do not invest much energy in photoprotection (e.g., pigments) or in upregulated DNA repair mechanisms (e.g., photolyase; Blaustein et al. 1994, 1996), which are known to be energetically costly. Photolyase activity increases in several amphibian species when UV-B jelly absorbance (i.e., protection) decreases (Smith et al. 2002). In high altitude environments, this energetic economy could benefit embryos and tadpoles that need to invest as much as possible in growth and development. At lower altitudes, UV-B levels decrease and tadpoles enjoy a longer activity period. The selective pressure on females via jelly compounds could be lower, but protection against the harmful effects of UV-B remains necessary. Photoprotection could thus be provided directly by embryos (e.g., pigmentation, efficient DNA repair mechanisms), without consequences to growth, development, and survival. Embryos without jelly from lowland populations exhibited this higher tolerance to UV-B to a greater extent than did manipulated embryos from highland populations (Fig. 3a).

Our results show significant geographic variation in UVB tolerance among $R$. temporaria populations in the northwest Alps, using ecologically relevant UV-B doses. The jelly coat surrounding the embryos played an important protective role, and a maternal effect was suspected. Maternal effects are known to be adaptive strategies (reviewed by Mousseau and Fox 1998). High altitude populations of $R$. temporaria have specific demographic traits (e.g., delayed age at sexual maturity, longevity), a low gene flow between populations (Pidancier 2003), and are exposed to harsh climatic conditions (Miaud et al. 1999; Miaud and Merilä 2001; Beebee and Griffiths 2005), all of which factors are known to favor local adaptation over plasticity (Kawecki and Ebert 2004). Genetically fixed maternal effect strategies were observed among plant populations along a wide environmental gradient and low interpopulational gene flow (Linhart and Grant 1996; Galloway 2005). Likewise, highland populations of $R$. temporaria could present adaptive maternal effects to protect embryos against UV-B damage. On the other hand, adverse conditions in high latitudes or altitudes severely constrain the evolution of physiological tolerances because of the substantial costs associated with these adaptive responses, thus leading to sub-optimal performances, a phenomenon often observed at the limit range of species distribution (Grace 1987; Parmesan 1996; Hoffmann and Blows 1994; Garner et al. 2004). The lower hatching survival observed at high altitude can thus illustrate that $R$. temporaria has reached its altitudinal limit.

Acknowledgments The authors are grateful to Dr. Sylvie Guittonneau for the technical assistance with the Suntest, and to Annie Millery, Sydney Morlet, Mélanie Arnaud, and Katy Morell for their help during field and laboratory work. We thank the two anonymous reviewers for their constructive comments.

\section{References}

Beebee TJC, Griffiths RA (2005) The amphibian decline crisis: a watershed for conservation biology? Biol Conserv 125:271285

Belden LK, Blaustein AR (2002) Population differences in sensitivity to UV-B radiation in larval long-toed salamanders. Ecology $83: 1586-1590$

Belden LK, Wildy EL, Blaustein AR (2000) Growth, survival and behaviour of larval long-toed salamanders (Ambystoma macrodactylum) exposed to ambient levels of UV-B radiation. J Zool 251:473-479

Blaustein AR, Belden LK (2003) Amphibian defences against ultraviolet-B radiation. Evol Dev 5:89-97

Blaustein AR, Wake DB (1995) The puzzle of declining amphibian populations. Sci Am 272:52-57

Blaustein AR, Hoffman PD, Hokit DG, Kiesecker JM, Walls SC, Hays JB (1994) UV repair and resistance to solar UV-B in amphibian eggs: a link to population declines? Proc Natl Acad Sci USA 91:1791-1795

Blaustein AR, Hoffman PD, Hokit DG, Kiesecker JM, Hays JB (1996) DNA repair activity and resistance to solar UV-B radiation in eggs of the Red-legged frog. Conserv Biol 10:1398-1402

Blumthaler M, Ambach W, Rehwald W (1992) Solar UV-A and UV$B$ radiation fluxes at two alpine stations at different altitudes. Theor Appl Climatol 46:39-44

Bonin A, Taberlet P, Miaud C, Pompanon F (2006) Explorative genome scan to detect candidate loci for adaptation along a gradient of altitude in the common Frog (Rana temporaria). Mol Biol Evol 23:773-783

Cockell CS, Blaustein AR (2001) Ecosystem, evolution, and ultraviolet radiation. Springer, New York Berlin Heidelberg

Corn PS (1998) Effects of ultraviolet radiation on boreal toads in Colorado. Ecol Appl 8:18-26

Crump P, Berrill M, Coulso D, Lean D, McGillivray L, Smith A (1999) Sensitivity of amphibian embryos, tadpoles, and larvae to enhanced UV-B radiation in natural pond conditions. Can J Zool 77:1956-1966

Cummins CP, Greenslade PD, McLeod AR (1999) A test of the effect of supplemental UV-B radiation on the common frog, Rana temporaria L. during embryonic development. Glob Change Biol 5:471-479

Galloway LF (2005) Maternal effects provide phenotypic adaptation to local environmental conditions. New Phytol 166:1-93

Gasc JP, Cabela A, Crnobrnja-Isailovic J, Dolmen D, Grossenbacher K, Haffner P, Lescure J, Martens H, Martinez Rica JP, Oliveira ME, Sofianidou TS, Veith M, Zuiderwijk A (1997) Atlas of amphibians and reptiles in Europe. Societas Europaea Herpetologica and Museum National d'Histoire Naturelle (IEGB/SPN), Paris 
Garner TWJ, Pearman PB, Angelone S (2004) Genetic diversity across a vertebrate species' range: a test of the central-peripheral hypothesis. Mol Ecol 13:1047-1053

Gosner KL (1960) A simplified table for staging anuran embryos and larvae with notes on identification. Copeia 1960:183-190

Grace J (1987) Climatic tolerance and the distribution of plants. New Phytol 106:113-130

Grant KP, Licht LE (1995) Effects of ultraviolet-radiation on lifehistory stages of anurans from Ontario, Canada. Can J Zool 73:2292-2301

Guyétant R, Miaud C, Battesti A, Nelva A (1994) Caractéristiques de la reproduction de la Grenouille rousse Rana temporaria L. (Amphibiens, Anoures) en altitude (Massif de la Vanoise, Alpes du nord, France). Bull Soc Herpetol Fr 71-72:13-21

Häkkinen J, Pasanen S, Kukkonen VK (2001) The effects of solar UV-B radiation on embryonic mortality and development in three boreal anurans (Rana temporaria, Rana arvalis and Bufo bufo). Chemosphere 44:441-446

Hansen L, Fabacher DL, Calfee R (2001) The role of the egg jelly coat in protecting Hyla regilla and Bufo canorus embryos from ultraviolet B radiation during development. Environ Sci Pollut Res 9:412-416

Hofer R, Mokri C (2000) Photoprotection in tadpoles of the common frog, Rana temporaria. J Photochem Photobiol B 59:48-53

Hoffmann AA, Parsons PA (1991) Evolutionary genetics and environmental stress. Oxford Science Publications, Oxford

Hoffmann AA, Blows MW (1994) Species borders: ecological and evolutionary perspectives. Trends Ecol Evol 9:223-227

Houlahan JE, Findley CS, Schmidy BR, Meyer AH, Kuzmin SL (2000) Quantitative evidence for global amphibian declines. Nature 404:752-755

Kawecki TJ, Ebert D (2004) Conceptual issues in local adaptation. Ecol Lett 7:1225-1241

Laugen AT, Laurila A, Rasanen K, Merila J (2003) Latitudinal countergradient variation in the common frog (Rana temporaria) development rates-evidence for local adaptation. J Evol Biol 16:996-1005

Licht LE (2003) Shedding light on ultraviolet radiation and amphibian embryos. Bioscience 53:551-561

Licht LE, Grant KP (1997) The effects of ultraviolet radiation on the biology of amphibians. Am Zool 37:137-145

Linhart YB, Grant MC (1996) Evolutionary significance of local genetic differentiation in plants. Annu Rev Ecol Syst 27:237277

Marquis O, Miaud C (2008) Variation in UV sensitivity among common frog Rana temporaria populations along an altitudinal gradient. Zoology (in press)

Martin R, Miaud C (1999) Reproductive investment and duration of the embryonic development in the common frog Rana temporaria (Amphibia: Anura) from low- to highland. In: Miaud C, Guyétant R (eds) Current studies in herpetology. Societas Europaea Herpetologica, Le Bourget du lac, pp 309-313

Merilä J, Pahkala M, Johanson U (2000a) Increased ultraviolet-B radiation, climate change and latitudinal adaptation-a frog perspective. Ann Zool Fenn 37:129-134

Merilä J, Laurila A, Pahkala M (2000b) Effect of ambient UV-B radiation on early development of the common frog (Rana temporaria) embryos in the subarctic. Ann Zool Fenn 37:51-58
Miaud C, Merilä J (2001) Local adaptation or environmental induction? Causes of population differentiation in alpine amphibians. Biota 2:31-50

Miaud C, Guyétant R, Elmberg J (1999) Variation in life-history traits in the common frog Rana temporaria (Amphibia: Anura): a literature review and new data from the French Alps. J Zool 249:61-73

Mousseau TA, Fox CW (1998) Maternal effects as adaptation. Oxford University Press, New York

Ovaska K, Davis TM, Flamarique IN (1997) Hatching success and larval survival of the frogs Hyla regilla and Rana aurora under ambient and artificially enhanced solar ultraviolet radiation. Can J Zool 75:1081-1088

Pahkala M, Laurila A, Merilä J (2000) Ambient ultraviolet-B radiation reduces hatchling size in the common frog Rana temporaria. Ecography 23:531-538

Pahkala M, Laurila A, Merilä J (2001) Carry-over effects of ultraviolet-B radiation on larval fitness in Rana temporaria. Proc R Soc Lond B 268:1699-1706

Pahkala M, Laurila A, Merilä J (2002) Effects of ultraviolet-B radiation on common frog Rana temporaria embryos from along a latitudinal gradient. Oecologia 133:458-465

Palen WJ, Schundler DE, Adams MJ, Pearl CA, Bury B, Diamond SA (2002) Optical characteristics of water protect amphibians from UV-B in the US Pacific Northwest. Ecology 83:2951-2957

Parichy DM, Kaplan RH (1995) Maternal investment and developmental plasticity: functional consequences of locomotor performance of hatchling frog larvae. Funct Ecol 9:606-617

Parmesan C (1996) Climate and species range. Nature 382:765-766

Pidancier N (2003) Analyse génétique spatialisée: le modèle Grenouille rousse (Rana temporaria). PhD thesis, University of Grenoble, Grenoble

Räsänen K, Pahkala M, Laurila A, Merilä J (2003) Does jelly envelope protect the common frog Rana temporaria embryos from UV-B radiation? Herpetologica 59:293-300

Räsänen K, Laurila A, Merilä J (2005) Maternal investment in egg size: environment- and population-specific effects on offspring performance. Oecologia 142:546-553

Salthe SN (1963) The egg capsules in the amphibian. J Morphol 113:161-171

SAS Institute (2000) SAS user's guide. Release 8.2. SAS Institute, Cary

Sinsch U (1984) Thermal influences on the habitat preference and the diurnal activity in three European Rana species. Oecologia 64:125-131

Tevini M (1993) UV-B radiation and ozone depletion: effects on humans, animals, plants, micro-organisms, and materials. Lewis, Boca Raton

Smith MA, Berrill M, Kapron CM (2002) Photolyase activity of the embryo and the ultraviolet absorbance of embryo jelly for several Ontario amphibian species. Can J Zool 80:1109-1116

Vences M, Grossenbacher K, Puente M, Palanca A, Vieites DR (2003) The Cambalès fairy tale: Elevational limits of Rana temporaria (Amphibia: Ranidae) and other European amphibians revisited. Folia Zool 52:189-202

Wood RJ, Bishop JA (1981) Insecticide resistance: populations and evolution. In: Bishop JA, Cook LM (eds) Genetic consequences of man made change. Academic, London, pp 97-128 